\title{
DIFFERENCES IN BODY PROPORTIONS BETWEEN HATCHERY-REARED- AND WILD PACIFIC HERRING, CLUPEA PALLASII (ACTINOPTERYGII: CLUPEIFORMES: CLUPEIDAE)
}

\author{
Mitsuhiro NAKAYA ${ }^{1 *}$, Kyohei FUKUNAGA ${ }^{2}$, and Shigenori SUZUKI ${ }^{3}$ \\ ${ }^{1}$ Faculty of Fisheries, Hokkaido University, Japan \\ ${ }^{2}$ Fisheries Research Agency, Hokkaido National Fisheries Research Institute, Akkeshi, Japan \\ ${ }^{3}$ Fisheries Research Agency, National Research Institute of Aquaculture, Minamiizu Laboratory, Japan
}

Nakaya M., Fukunaga K., Suzuki S. 2013. Differences in body proportions between hatchery-reared- and wild Pacific herring, Clupea pallasii (Actinopterygii: Clupeiformes: Clupeidae). Acta Ichthyol. Piscat. 43 (1): $75-77$.

\begin{abstract}
The body proportions of 0-group Pacific herring, Clupea pallasii, were compared between hatcheryreared- and wild fish and significant differences were observed. There were fewer vertebrae (Mean \pm SD) in hatchery-reared- $(52.5 \pm 2.15)$ than in wild fish $(53.7 \pm 0.92)$. For both the hatchery-reared- and the wild individuals, the correlations between number of vertebrae and vertebral column length (VCL) per standard length (SL) were positive. Head length (HL) was approximated as SL minus VCL. Therefore, the proportion of HL in relation to SL became lower with the higher number of vertebrae. Their vertebral number may relate to the difference of body proportions between hatchery-reared- and wild fish.
\end{abstract}

Keywords: body proportions, hatchery-reared, Pacific herring, number of vertebrae

The quality of hatchery-reared fish depends on the physiology, morphology, and behaviour, which directly relate to their ability to survive under natural conditions (Masuda and Tsukamoto 1998). Moreover, negative effects on commercialization may occur, since hatchery-reared fish have been shown to have differences in body morphology compared to wild fish (Koumoundouros et al. 1997, Loy et al. 1999). Pacific herring, Clupea pallasii Valenciennes, 1847, is one of the most important fish for stock enhancement ventures in northern Japan, and in 2008 the total number of juveniles released was 6949 000. However, morphological abnormalities and skeletal deformities in this species are commonly observed in hatcheries. Juveniles of the Pacific herring measuring $50-70 \mathrm{~mm}$ in total length (TL) were produced in a hatchery at the Akkeshi Laboratory, Hokkaido National Fisheries Research Institute, Fisheries Research Agency, Hokkaido and released in the Akkeshi Bay on 1 August 2004. This paper compares the body proportions of 0-group Pacific herring between hatcheryreared- and wild fish that were collected in the Akkeshi Bay on 30 October 2004. We also discuss the reasons for their morphological differences (excluding individuals with skeletal deformities).

Well matured Pacific herring were caught with a gill net in the Akkeshi Bay on 13-14 April 2004, and eggs were artificially fertilized by the dry method on 14 April 2004 . The eggs were stocked and then incubated in a $50-\mathrm{m}^{3}$ con- crete tank at a mean water temperature $8.4^{\circ} \mathrm{C}$. After hatching, the larvae were reared in the same tank at an initial density of 7400 individuals per $1 \mathrm{~m}^{3}$ under optimal temperature conditions (mean: $13.0^{\circ} \mathrm{C}$, range: $11.8-13.7^{\circ} \mathrm{C}$ ) for larval and juvenile culture of this species (Yamamoto 2001). Larvae were fed rotifers, Brachionus plicatilis, from 2 to 20 days after hatching (DAH). From 10 to $60 \mathrm{DAH}$, the larvae and juveniles were fed Artemia salina nauplii. The rotifers and Artemia salina nauplii were enriched with a commercial enrichment material (Plus Aquaran, BASF Japan). Dry feed (Otohime A, B1, and B2: Nisshin Marubeni Co. Ltd.) was given from 20 DAH until the end of the rearing (reaching about $50-70 \mathrm{~mm} \mathrm{TL}$ ). The daily water exchange rates were adjusted and increased according to their growth (0-93 DAH: $50 \%-250 \%)$. Mean oxygen saturation of the circulating water was $122 \%$ (range: $119 \%-126 \%$ ). Those values exceeded the tolerance level of Pacific herring in terms of the gas-bubble disease threat (115\%: Yamamoto 2001). Therefore, the oxygen saturation revel was reduced below $110 \%$ using strong aeration and regulation of the water temperature in a reservoir tank before the rearing. Mean $\mathrm{pH}$ was 7.8 (range: 7.2-8.1). In the rearing period, these larvae were otolith marked using alizarin complexone (ALC) solution (concentration $40 \mathrm{mg} \cdot \mathrm{L}^{-1}$ ) as a mark of hatchery-reared fish. On 1 August 2004, a total of 293000 individuals of the hatchery-reared fish were released in the Akkeshi Bay. In the

\footnotetext{
* Correspondence: Dr. Mitsuhiro Nakaya, Faculty of Fisheries, Hokkaido University, Hakodate, Hokkaido 041-8611, Japan, phone: +(81)138405526, fax: +(81)138405526, e-mail: mnakaya@fish.hokudai.ac.jp.; nakayamitsuhiro@yahoo.co.jp.
} 
pre-release research, the occurrence rate of compressed and fused vertebrae was $4.6 \%$, while other morphological abnormalities occurred in $1.4 \%$ of the fish (lack of a part of opercular region: $0.7 \%$, projection of isthmus faucium: $0.7 \%)$. Zero group Pacific herring were caught $(n=111)$ with a boat seine net in Akkeshi Bay on 30 October 2004. Standard length (SL: from tip of snout to posterior most end of hypural plates) and head length (HL: from tip of snout to the margin of gill cover) of Pacific herring were measured to the nearest $0.1 \mathrm{~mm}$. We measured vertebral column length (VCL: distance from anterior most part of first vertebra to end of hypural plates) and checked for deformity with fused and/or compressed vertebrae and counted the number of vertebrae using a soft X-ray Photograph (C-60, SOFTEX Corporation), and then the otoliths were extracted. The otoliths marked with ALC were detected under a fluorescence microscope to distinguish hatchery-reared- from wild fish. Compressed and fused vertebrae are one of the main factors for morphological abnormality (especially shortened body) of Pacific herring (Yamamoto 2001). In this study, except for examination of the influence of skeletal deformities, we used only individuals without skeletal deformities (hatchery-reared: 19 whole samples, wild: 20 random samples) for the purpose of comparison of body proportions between hatcheryreared and wild individuals. Welch's $t$-test was used to compare the mean values.

No significant difference (Welch's $t$-test, $P=0.90$ ) was found in SL between hatchery reared- (Mean \pm standard deviation: $114.4 \pm 7.35 \mathrm{~mm}, n=19$ ) and wild fish (114.1 $\pm 4.06 \mathrm{~mm}, n=20)$. We compared the proportion of HL to SL between hatchery-reared- and wild fish of Pacific herring (Fig. 1). The hatchery-reared fish had higher values of HL to SL compared to the wild fish (Welch's $t$-test, $P<0.05)$. The number of vertebrae showed lower values in hatchery-reared- $(52.5 \pm 2.15,50-54)$ than in

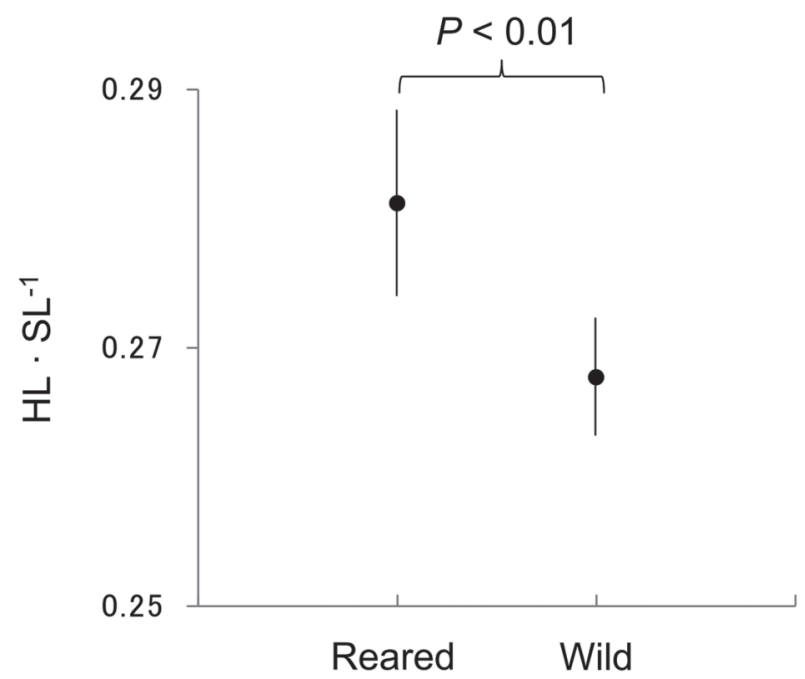

Fig. 1. Comparison of head-length (HL) to body-length (SL) proportion of hatchery-reared- (reared) $(n=19)$ and wild $(n=20)$ Pacific herring, Clupea pallasii wild fish $(53.7 \pm 0.92,52-55)$ (Welch's $t$-test, $P<0.05)$. We differentiated their vertebrae into abdominal- and caudal ones. The number of abdominal vertebrae showed lower values in hatchery-reared- $(29.1 \pm 2.32,24-32)$ than in wild fish $(30.8 \pm 1.00,29-32)$ (Welch's $t$-test, $P<0.01)$. No significant differences were observed, however, in the number of caudal vertebrae (Welch's $t$-test, $P=0.10$; hatchery reared: $23.2 \pm 0.98,21-25$; wild: $22.8 \pm 0.72$, 21-24). Yoshimura and Kawashita (2003) showed that hatchery-reared bastard halibut, Paralichthys olivaceus (Temminck et Schlegel, 1846), had a lower caudal vertebral number than wild specimens. Our results for Pacific herring suggest that the number of abdominal vertebrae will vary more than that of caudal vertebrae. Fish from higher latitudes and colder waters tend to have a higher number of vertebrae than related fish from lower latitudes and warmer waters (Jordan 1891). Temperature is considered the operational factor in Jordan's rule, as the relation between vertebral numbers and rearing temperature during early life stages is negative in most cases (Lindsey 1988). For both the hatchery-reared- and the wild individuals, the correlations between the number of vertebrae and VCL $\cdot \mathrm{SL}^{-1}$ was positive (hatchery-reared: $R=0.59, P<0.01, n=19$; wild: $R=0.59, P<0.01, n=20$; Fig. 2). Head length was approximated as SL minus VCL. Therefore, the proportion of HL occupied by SL becomes lower with the higher numbers of vertebrae. Balbontin et al. (1973) compared the body form of laboratory-reared- and sea-caught young 0-group Atlantic herring, Clupea harengus L., of a similar size range. Their result shows that laboratory-reared fish had a bigger head compared to the wild fish; our study showed the same results. In addition, these results suggest that the reason would be number of vertebrae - showing lower values in hatchery-reared- than in wild fish. Rogdakis et al. (2011) demonstrated that the head of gilthead seabream, Sparus aurata L., reared in cages was

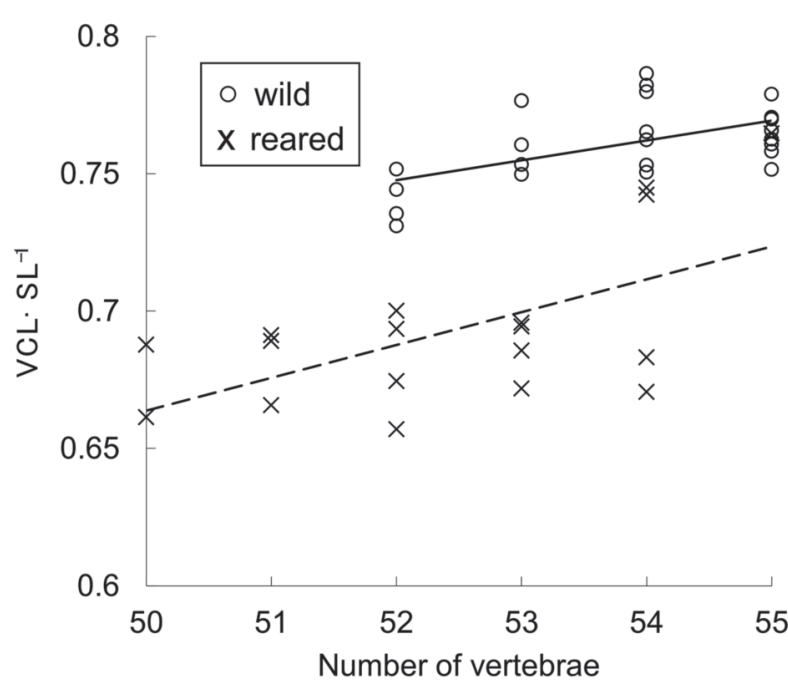

Fig. 2. Correlation between number of vertebrae and vertebral column length (VCL) per body length (SL) of hatchery-reared- (reared) $(n=19)$ and wild $(n=20)$ Pacific herring, Clupea pallasii 
longer than that of wild fish and released hatchery-reared fish of the same body length, while between wild- and released hatchery-reared fish the head length did not differ. Thus, the morphology tends to change with the environmental condition. However, the vertebral number that is the focus of this study did not change once constructed, the rate of $\mathrm{HL} \times \mathrm{SL}^{-1}$ would stabilise to some extent when the vertebrae are fully formed. In some fish species, morphological differences between hatchery-reared- and wild fish, as well as the skeletal deformities have been observed in hatcheries (Marino et al. 1993, Boglione et al. 2003). Previous studies reported that the main reason for the different body proportions between hatchery-reared- and wild fish would be morphological differences and/or skeletal deformities (Yoshimura and Kawashita 2003, Gavaia et al. 2009). In addition, this study presented evidence that the number of vertebrae may be related to the difference of body proportion between hatchery-rearedand wild fish.

From mid- to late April, Akkeshi Lake which is the main nursery area of the Pacific herring stock (Shirafuji et al. unpublished data), the mean water temperature of $8.6 \pm 0.99^{\circ} \mathrm{C}($ mean $\pm \mathrm{SD} ; 2004)$ was lower than the rearing temperature (mean: $13^{\circ} \mathrm{C}$ ). Tester (1949) explained that the variation in average number of vertebrae of Pacific herring was inversely correlated with the variation in general water temperature prevailing in the period of early development. Our results also indicate that the number of vertebrae may be determined by the water temperature in particular at an early life stage.

\section{ACKNOWLEDGMENTS}

We thank the staff of the Hokkaido National Fisheries Research Institute, Fisheries Research Agency, Akkeshi who helped with the laboratory experiments: Yusuke Bando, Sachiko Degoshi, Mieko Genta, Shimako Hashimoto, Michiko Okuizumi, and Yuko Suzuki. Two referees provided valuable comments on the manuscript. The text has been proofread by the Japan Scientific Text (JST).

\section{REFERENCES}

Balbontin F., De Silva S.S., Ehrlich K.F. 1973. A comparative study of anatomical and chemical characteristics of reared and wild herring. Aquaculture 2: 217-240. DOI: 10.1016/0044-8486(73)90155-5

Boglione C., Costa C., Di Dato P., Ferzini G., Scardi M., Cataudella S. 2003. Skeletal quality assessment of reared and wild sharpsnout sea bream and pandora juveniles. Aquaculture 227 (1-4): 373-394. DOI: 10.1016/S00448486(03)00515-5

Gavaia P.J., Domingues S., Engrola S., Drake P., Sarasquete C., Dinis M.T., Cancela M.L. 2009. Comparing skeletal devel- opment of wild and hatchery-reared Senegalese sole (Solea senegalensis, Kaup 1858): evaluation in larval and postlarval stages. Aquaculture Research 40 (14): 1585-1593. DOI: 10.1111/j.1365-2109.2009.02258.x

Jordan D.S. 1891. Relations of temperature to vertebrae among fishes. Proceedings of the United States National Museum 14: $107-120$.

Koumoundouros G., Gagliardi F., Divanach P., Boglione C., Cataudella S., Kentouri M. 1997. Normal and abnormal osteological development of caudal fin in Sparus aurata L. fry. Aquaculture 149 (3-4): 215-226. DOI: 10.1016/S00448486(96)01443-3

Lindsey C.C. 1988. Factors controlling meristic variation. Pp.197-274. In: Hoar W.S., Randall D.J. (eds.) Fish physiology. Vol. 11. Part B. Academic Press, San Diego California, USA.

Loy A., Boglione C., Cataudella S. 1999. Geometric morphometrics and morpho-anatomy: a combined tool in the study of sea bream (Sparus aurata, Sparidae) shape. Journal of Applied Ichthyology 15 (3): 104-110. DOI: 10.1046/j.14390426.1999.00116.x

Marino G., Boglione C., Bertolini B., Rossi A., Ferreri F., Cataudella S. 1993. Observations on development and anomalies in the appendicular skeleton of sea bass, Dicentrarchus labrax L. 1758, larvae and juveniles. Aquaculture Fishes Management 24 (3): 445-456. DOI: $10.1111 / \mathrm{j} .1365-2109.1993 . t b 00568 . x$

Masuda R., Tsukamoto K. 1998. Stock enhancement in Japan: Review and perspective. Bulletin of Marine Science 62 (2): 337-358

Rogdakis Y.G., Koukou K.K., Ramfos A., Dimitriou E., Katselis G.N. 2011. Comparative morphology of wild, farmed and hatchery-released gilthead sea bream (Sparus aurata) in western Greece. International Journal of Fisheries and Aquaculture 3 (1): 1-9.

Tester A.L. 1949. Populations of herring along the west coast of Vancouver Island on the basis of mean vertebral number, with a critique of the method. Journal of the Fisheries Research Board of Canada 7c (7): 403-420. DOI: 10.1139/f47-032

Yamamoto Y. 2001. Seed production of Pacific herring Clupea pallasii. Stock Enhancement Technology Series No. 7. Nihon Saibaigyogyou Kyokai, Tokyo, Japan. [In Japanese.]

Yoshimura K., Kawashita M. 2003. Comparison of body proportions and meristic characters between hatchery-reared and wild Japanese flounder juveniles. Scientific Reports of Hokkaido Fisheries Experimental Station 64: 105-111. [In Japanese.]

Received: 8 November 2012

Accepted: 16 February 2013

Published electronically: 31 March 2013 